\title{
Suppressed eusocial reproduction supports evolutionary convergence over co-option
}

\author{
Velasque, M. ${ }^{1}$, Tan, Y. ${ }^{1}$, Liu, A.W. ${ }^{1}$, Luscombe, N.M. ${ }^{1}$ \& Denton, J.A. ${ }^{1,2, \#}$ \\ ${ }^{1}$ Genomics \& Regulatory Systems Unit, Okinawa Institute of Science \& Technology, 1919-1 \\ Tancha, Okinawa, Japan \\ ${ }^{2}$ Institute of Vector-borne Disease, Monash University, Clayton, Victoria, Australia \\ \# Corresponding author: jai.denton@monash.edu
}

\section{Abstract}

Eusocial insects are characterized by the presence of division of labour between reproductive (i.e. workers) and non-reproductive (i.e. queens) individuals. In eusocial insects, such as wasps, ants, honeybees and termites, such reproductive division of labour is mediated by the use of unique pheromones. In eusocial animals, pheromones control two distinct aspects of the division of labour: reproduction and division of tasks amongst workers. It has been suggested that eusociality arose independently on several occasions from pheromone-mediated co-option of pathways regulating the reproductive life cycle of solitary insects. Transcriptomic analysis has supported the cooption of similar pathways in each independently evolved eusocial insect. Using a solitary insect model, we sought to determine if these similar transcriptomic signals resulted from the co-option of similar pathways or varying pathways subject to convergent evolution. We measured the transcriptomic and physiological response of Drosophila melanogaster to pheromones from bumblebees, honey bees, and termites. In each case we observed a strong physiological response - the reduction of ovary size. However, employing conventional differential gene expression analysis and several forms of network analysis, we were unable to detect any conserved pathway or genes acting as a primer for eusociality. This strongly suggests that pheromone-mediated eusociality is the result of convergent evolution. Wherein a physiological response, such 
bioRxiv preprint doi: https://doi.org/10.1101/2021.07.11.451940; this version posted July 14, 2021. The copyright holder for this preprint (which was not certified by peer review) is the author/funder. All rights reserved. No reuse allowed without permission.

as reduced reproductive capacity, acts as the primer for eusociality and is subsequently refined. 


\section{Introduction}

The transition from solitary to group living is one of the major evolutionary transitions (1). In order to better adapt to group living, animals developed complex communication mechanisms that allow the transference of essential information such as the presence of predators or resource location $(2,3)$. Although there are multiple methods to transmit and receive information (e.g. visual, auditory, electric, olfactory), the use of chemical cues is one of the most important and earliest to evolve $(2,4)$. For instance, insects use chemical components to find mates, recruitment, defence, predator recognition, and mate attraction (5-7). However, chemical cues are not limited to simply conveying information; they can shape social interactions.

Within social insects, chemical communication has evolved beyond contextdependent messaging. Pheromones, such as queen (QP) and brood pheromone $(\mathrm{Br})$ in Apis mellifera (honey bee), can induce long-term behavioural and physiological effects $(8,9)$. These are referred to as primer pheromones and they have a great effect on colony dynamics $(9,10)$, ranging from modulating aggression and attraction to the monopolization of colony reproduction through the regulation of female fecundity ( 11 , 12). This monopolization of reproduction by a few or one group (queens/kings) creates a division of labour (DOL) $(8,9)$ and is the cornerstone of eusociality $(13-16)$.

In eusocial animals, division of labour can occur in two ways, between queens and workers for reproduction (reproductive division of labour) and between workers for nest related tasks (task division). Although intrinsically distinct, it has been suggested that these two aspects of the division of labour (reproductive and division of tasks) are intertwined, arising from modifications of the reproductive life cycle of solitary insects $(17,18)$. Comparative genetics amongst multiple eusocial insects corroborates this hypothesis and suggests that eusocial traits evolved from the co-option of pathways present in solitary ancestors (19-23), through parallel evolution. Further support for this hypothesis is that eusociality has evolved multiple times independently within insects (between 8 and 11 times), but is otherwise rare throughout the animal kingdom (24). However, clear unambiguous evidence remains elusive $(20,25)$.

In eusocial insects, the caste differentiation process is usually initiated in the early larval stage and maintained throughout adulthood, in most eusocial species, via 
pheromones. For instance, without QP and $\mathrm{Br}$, reproductive and task-related division of labour breaks down and workers behaviour and physiology becomes less eusocial (2629). As such, the presence of pheromones is an essential cornerstone of the evolution and maintenance of eusociality and likely the result of strong selection that can be traced back to the solitary ancestral of eusocial insects. In fact, there is strong evidence that QP in eusocial insects evolved multiple independently from conserved signals of solitary ancestors $(23,30,31)$. Despite the assumption that eusociality in insects is an example of parallel evolution, little is known about pheromone effects beyond their physiological and behavioural mediated changes (22). Moreover, cross-species comparisons are rare, especially examining transcriptomic changes (22). Although transcriptomic comparisons are complicated due to the evolutionary distances between eusocial insects; inter-species gene orthologs may have vastly different functions (3234).

Therefore, differences in expression patterns between two highly divergent species can be highly misleading. This is the case of the two major eusocial groups, termites (Isoptera) and hymenopterans, that are separated by over 350 Myr (35). Thus, pheromone-induced transcriptomic changes reflect extensive evolutionary optimisation of affected networks. One approach to overcome this problem is to investigate transcriptomic changes induced by varying pheromones in a single species. This permits the study of conserved and co-opted transcriptomic changes and identifies molecular signatures of these rare evolutionary events.

Here, we investigate how pheromones alter physiology and gene expression in a solitary ancestral. Using Drosophila melanogaster as our solitary animal, we tested the hypothesis that primer pheromones regulating eusociality evolved from the co-option of similar pathways present in solitary ancestors. In other words, we investigated whether distinct pheromones have a similar profile, genetic and physiological, across multiple instances on which it evolved, as previously suggested. We expect that synthetic primer pheromones (QP and $\mathrm{Br}$ ) will regulate the reproductive state of $D$. melanogaster, as it regulates it's eusocial counterpart, reducing fecundity. We also expect that such analogous physiological response will be reflected on its genetic pathway, with different pheromones producing similar expression patterns in $D$. melanogaster. We present a 
comprehensive transcriptome dataset set investigating gene expression associated with reproductive division of labour associated with QP and $\mathrm{Br}$ produced by termites (Reticulitermes speratus QP), bumblebees (Bombus terrestris QP) and honey bees (Apis mellifera QP and $\mathrm{Br}$ ). We leverage this data set to perform, to our knowledge, the most up to date comparison of differentially vs distinct (i.e. non-homologous) expressed genes associated with the maintenance of eusociality.

\section{Results}

\section{Pheromone-induced Ovary Changes}

We identified a significant change in ovary size across all pheromone treated $D$. melanogaster relative to solvent only controls $\left(F_{6,180}, p<0.0001\right.$; Figure 1$)$. We did not find significant differences in ovary size between the two controls ( $p=1.0$; Figure 1). Although pheromone treatment strongly inhibited oogenesis and thereby reduced ovary size, their effects varied in strength. Bumblebee and Termite pheromone had similar ( $p$ $=1$ ) severe pheromone-mediated ovary reductions of $0.32 \mathrm{~mm}^{2}$ and $0.35 \mathrm{~mm}^{2}$ (mean; $\mathrm{n}=10$ ) respectively. pheromone treatments $\mathrm{QMP}$, Brood and the mixed of QMP and Brood pheromone induced similar reductions on ovary size (QMP and Brood vs QMP $p$ $=1$; QMP and Brood vs Brood $p=1$; QMP vs Brood $p=0.064)$ of $0.51 \mathrm{~mm}^{2}, 0.65 \mathrm{~mm}^{2}$ and $0.59 \mathrm{~mm}^{2}$ (mean; $\mathrm{n}=10$ ) respectively. 


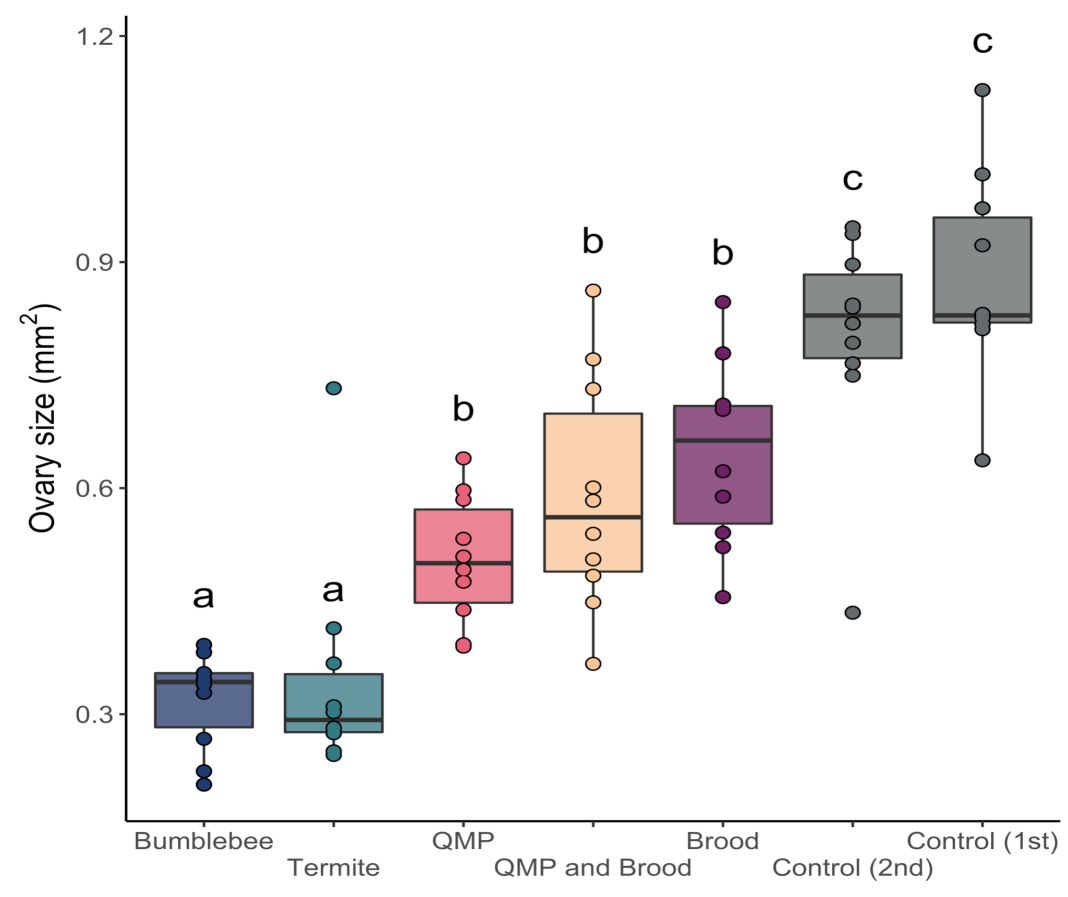

Figure 1 - Pheromone treatment resulted in reduced ovary size. Pheromones from Bumblebees, Termites, QMP, brood and a mix of QMP and brood were introduced to $D$. melanogaster via supplementation in food. Each data point represents the average of 3 technical replicates with each treatment/control having ten biological replicates.

\section{Pheromone-induced Transcriptomic Changes}

\section{Differentially expressed genes}

Using conventional differential gene expression analysis, edgeR, we identified no overlap between pheromone treatment groups. Within each treatment we identified similar numbers of differentially expressed genes -QMP (83 genes), Brood (328 genes), QMP and Brood (64 genes), Termites (47 genes) and Bumblebees (83 genes). There was no shared core of pheromone response genes and very little inter-treatment overlap (Figure 2B). As we were unable to identify a core of differentially expressed genes, we investigated if pheromone-mediated changes in gene expression affected reproductive physiology through similar cellular processes. We compared gene enrichment of pheromone induced changes in the transcriptome using GO (gene ontology) and KEGG (Kyoto Encyclopedia of Genes and Genomes) annotations. We found that differentially expressed genes were significantly enriched across all 
treatment groups, however, we failed to identify a shared enriched term or pathway (Figure 2A; and Supplementary Figures S6-S8, S11-S14, S16-S19, ).

The absence of differential gene expression or pathway core does not preclude the presence of gene expression networks driving pheromone response. To investigate pheromone mediated changes in genetic pathways and transcriptomic networks, we employed two different network analysis approaches: the identification of key hub genes and their respective change in expression in response to pheromone.

\section{Network Analysis}

Employing two complementary network-based approaches, WGCNA and Differential Network Expression (DNE), we were unable to identify a shared regulatory network (Supplemental Figure S10, S15) common between all pheromone treatments. DNE identified several statistically significant differentially co-expressed genes between the control groups and D. melanogaster treated with QMP (203 genes), Brood (276 genes), the mixed of QMP and Brood (593 genes), Termites (1138 genes) and Bumblebees (398 genes). The highly similar WGCNA results are available in Supplementary Material 3. Furthermore, GO enrichment (Supplemental Figure S11,) and Pathway Analysis (Supplemental Figure S13-S14) for these differentially coexpressed genes also failed to identify high levels of overlap between functions (Supplemental Figure S16-S19). 


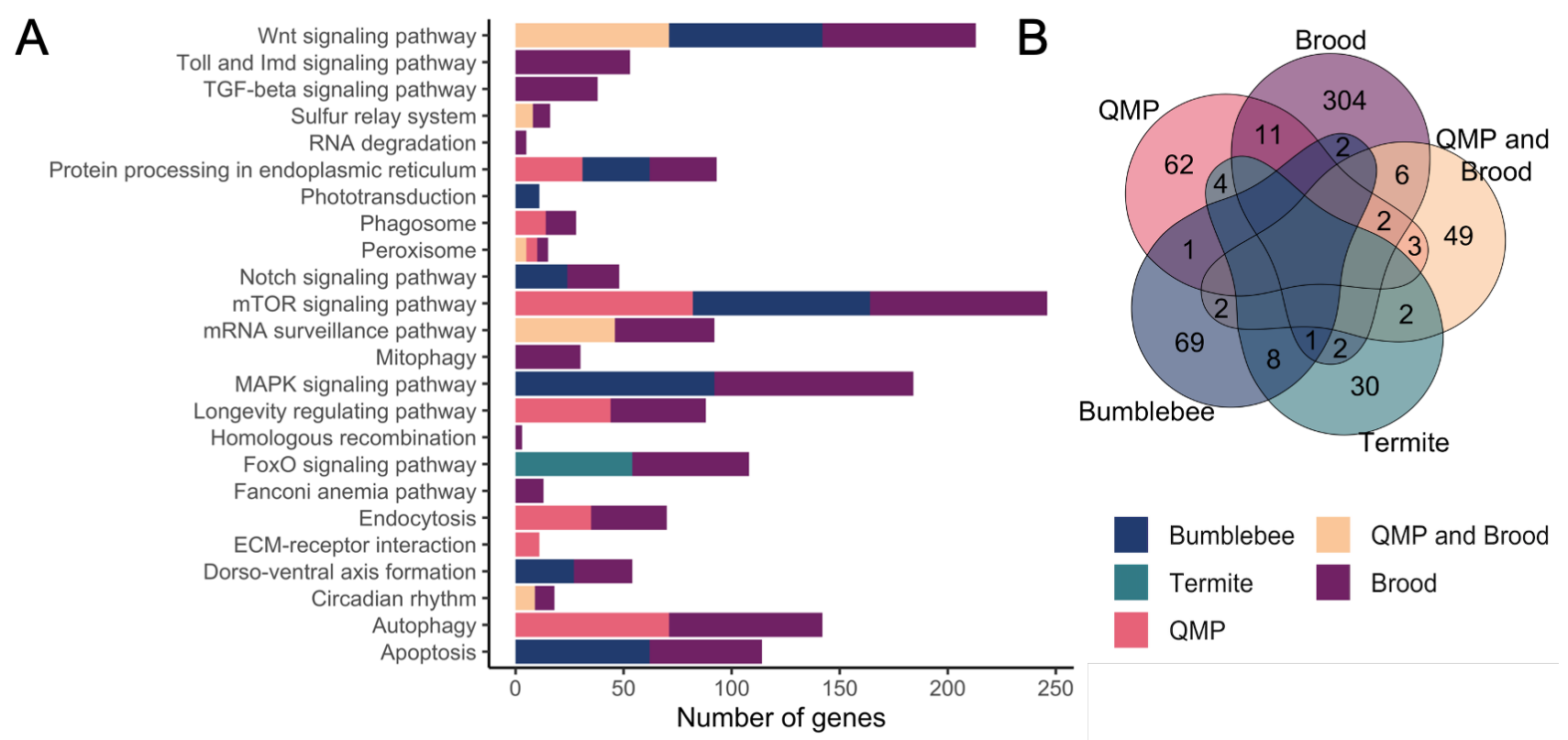

Figure 2 - Pheromone sensitive pathways and genes in Drosophila melanogaster do not show a shared response. A) Results of signaling pathway analysis of differentially expressed genes across different pheromone treatments. B) Venn diagram showing the number of significantly differentially expressed genes per pheromone treatment

\section{Cross-species comparison: are changes in Drosophila melanogaster comparable to} eusocial insects?

We found strong preservation in pheromonal response between eusocial insects and $D$. melanogaster. Although D. melanogaster has been previously used as a model organism in the study of eusociality (36), there are no direct comparisons between pheromone-mediated changes in gene expression for flies compared to eusocial insects. Holman et al. (22) studied the transcriptomic response of several species, including Apis mellifera and Bombus terrestris treated with either solvent-only control or their own species' pheromone. To determine whether the pheromone network signature was well conserved between Drosophila melanogaster, Apis mellifera (honey bees) and Bombus terrestris (bumblebees), we calculated the preservation statistics using WGCNA integrated function (modulePreservation). We identified 262 preserved genes between $D$. melanogaster and $A$. mellifera and 34 between $D$. melanogaster and $B$. 
terrestris. We also found that the majority of conserved genes were also differentially expressed between control and treatment (Supplemental Figure S15).

\section{Discussion}

Chemical communication greatly modulates insect behaviour $(7,37,38)$ but in social insects, such mechanisms have been independently co-opted in numerous species to facilitate the inhibition of worker reproduction by dominant females, the socalled queen pheromones $(4,5)$. Although eusociality is widely studied, the mechanisms of pheromonal induced worker sterility remain largely unresolved $(22,39)$. The prevailing hypothesis is that this induced sterility evolved from modifications in conserved molecular pathways regulating the physiology and behaviour of solitary species (22, 23, 40-42). Studies comparing queen pheromone-induced molecular effects in individual adults are scarce, but there is evidence they have a preserved molecular pathway (22). Therefore, it is reasonable to expect a similar pheromoneinduced response between different lineages of insects and thus result in similar physiological and regulatory pathway responses. Rather than comparing across eusocial species, we sought to remove the complexities of cross-species analysis by applying pheromone known to inhibit worker reproduction from honeybees, bumblebees and termites. Although all pheromone treatments suppressed ovary development in $D$. melanogaster, we did not find evidence for the presence of a shared evolutionary pathway amongst eusocial insects.

Our results suggest that pheromones produced by different eusocial insects do not produce a common molecular signature that can explain the origin and evolution of eusociality. Accordingly, both GO enrichment and pathway analysis also revealed a similar trend, with no overlap of functional categories across all pheromone treatments. We did, however, find a large set of differentially co-expressed genes being shared in at least one treatment group (Figure 2B and Supplemental Figure S10).

It has previously been shown pheromone exposure activates pathways related to lipid biosynthesis, oogenesis and olfaction $(22,23,42)$. They also showed the effect 
of major gene groups responsible for caste differentiation between queens and workers. For instance, Notch appears to be an essential pathway regulating ovary development in the presence of queen pheromone (42) and it is generally assumed to be one of the co-opted pathways in solitary animals enabling eusociality. Although we found Notch to be differentially co-expressed across all groups except brood and bumblebee pheromones, different pheromones activated different Notch signalling genes. Similarly, the yellow gene family (yellow-h and yellow-g2) was differentially co-expressed across all groups except for the Brood treatment. Yellow is a gene family present in most insects and some bacteria (43). In Hymenoptera, the yellow family is also responsible for the resolution of different aspects of eusociality, being one of the main components of royal jelly, the Major Royal Jelly Protein (MRJP) $(44,45)$.

We identified honey bee pheromones (QMP, QMP + Br and Br) to produce the most unique, weakest transcriptional and physiological response to pheromones. This unique trait has been previously shown by Holman et al. (22), who found QMP to produce a weaker transcriptional expression when compared to other species. Different from other eusocial insects, Apis queen pheromone is a blend of fatty-acid derived molecules, secreted by the mandibular gland $(46,47)$. Similarly, brood pheromone is a blend of fatty-acid esters found on the cuticles of honeybee larvae, being also part of the queen pheromone blend $(13,48)$. The similarity of our results provides further support that Apis mellifera workers might have evolved elevated sensitivity to pheromones, allowing a stronger control. Alternatively, it is also possible that in this group reproductive control is achieved through a combination of several other factors, such as a higher expression of brood pheromone and behaviours as worker policing $(49,50)$. Therefore, it is possible that worker policing ensures a lower reproductive success of remaining workers, selecting individuals with a higher physiological response to QMP.

Although such an experiment was conducted in Drosophila melanogaster, it seems to accurately depict the effect of QP in eusocial species. When comparing our results with the transcriptome of honey bees and bumblebees exposed to QP (22), we found strong conservation of differentially expressed genes in pheromone treatment. Demonstrating the reliability of our results and the importance of comparing the effect of 
distinct components (i.e. pheromones) into a single species, such as Drosophila. Reducing then, the low reliability of data when comparing distinct subsets of genes in different lineages without detectable orthologs.

Our work demonstrates how eusociality may have evolved. The first steps of eusocial evolution likely began with a localised impediment to reproduction that, over time, resulted in quasi-eusocial living. The absence in our work of a core pheromoneinduced transcriptomic response, and yet conserved phenotypic response, suggests female fertility suppression can rapidly evolve using numerous compounds that induce regulatory changes. This is evident as eusociality has evolved independently at least 8 times with limited overlap between the specific pheromones meditating this $(51,52)$.

Insect oogenesis is a highly sensitive process disrupted by numerous environmental, developmental and gene regulatory factors $(53,54)$. This includes the fact that cell death in the ovary is distinct from other tissues and mediated independently $(53,54)$. Therefore, oogenesis is a key candidate for pheromonemediated disruption and the evolution of eusociality.

\section{Conclusion}

The primer pheromonal signal in insects originated at least 100Mya and evolved independently in multiple species. Their evolution and signal can be well traced across three different groups: Blatoidea, Hymenoptera and Coleoptera, causing virtually a similar phenotype in all groups. The independent evolution of pheromones, the high conservation with their eusocial counterpart, combined with our results (i.e. pheromone treatment causing the similar ovary reaction in flies with no overlapping gene network and pathways) suggests pheromones are not a product of gene co-option, but the result of convergent phenotypic evolution. Producing a similar phenotype (inhibition of ovary development) through a different pathway in the species on which it evolved.

\section{Methods}

We used the fruit fly Drosophila melanogaster, to investigate the hypothesis that eusociality evolved multiple times by co-opting existing regulatory pathways present in a 
solitary ancestor. We achieved this by studying the pheromone genetic signature of fruit fly exposed to pheromones from three different eusocial species: honey bee queen mandibular pheromone (QMP), bumblebee queen pheromone (Bu), termite queen pheromone $(\mathrm{T})$ and a pheromone produced by honey bee larvae, the brood pheromone $(\mathrm{Br})$. To simulate conditions present in honey bee colonies, when they are exposed to both brood and queen pheromone, we also added a group with a mix of queen and brood pheromone (QMP + Br).

\section{Fly husbandry}

Flies were raised on standard Bloomington media at $24{ }^{\circ} \mathrm{C}$ under a $16 \mathrm{~h}$ light / $8 \mathrm{~h}$ dark cycle in $50 \mathrm{~mL}$ vials. The $D$. melanogaster strain Canton-S, a generous gift from the Van Vactor Unit, was used in all experiments. Each experimental vial contained 10 each of male and female approximately 5 day old flies and each treatment consisted of 10 vial replicates.

\section{Pheromone treatment}

Bloomington fly food was made and allowed to cool to $>60^{\circ} \mathrm{C}$ before mixing in each of the phenomenon treatments (Table 2) at a $1 \mathrm{in} 150 \mathrm{ml}$ concentration. Ten millilitres of supplemented food was added to each vial and left to dry for 24 hours. Vials were kept at $25^{\circ} \mathrm{C}$ and under a powerful extractor to prevent cross-contamination due to pheromone volatility. Adult flies were left on the vial for four days to lay eggs and then removed and discarded. Virgin females were collected and allowed to mature for 5 days in vials containing the aforementioned food with the corresponding treatment pheromone. 
Table 2 - Pheromone Treatments, suppliers, and dilution

\begin{tabular}{|c|c|c|c|}
\hline Treatment & Pheromone Formula & Supplier (ID) & Dilution \\
\hline Control & - & - & $50 \mu \mathrm{l}$ isopropanol \\
\hline QMP & $\begin{array}{l}\text { 9-ODA, two isomers of } \\
\text { 9-HDA, HOB and HVA }\end{array}$ & TempQueen (DC-705) & $\begin{array}{l}20 \mu \mathrm{l} \text { QMP mix diluted } \\
\text { in } 30 \mu \mathrm{l} \text { isopropanol }\end{array}$ \\
\hline Brood pheromone & $\begin{array}{l}\text { Methyl palmitate, Ethyl } \\
\text { palmitate, Methyl } \\
\text { stearate, Ethyl stearate, } \\
\text { Methyl oleate, Ethyl } \\
\text { oleate, Methyl linoleate, } \\
\text { Ethyl linoleate, Methyl } \\
\text { linolenate, Ethyl } \\
\text { linolenate }\end{array}$ & Contech (SuperBoost) & $\begin{array}{l}10 \mu \mathrm{l} \text { SuperBoost } \\
\text { diluted in } 40 \mu \mathrm{l} \\
\text { isopropanol }\end{array}$ \\
\hline $\begin{array}{l}\text { Bumblebee queen } \\
\text { pheromone }\end{array}$ & $\begin{array}{l}\text { CHC pentacosane } \\
\text { (C25) }\end{array}$ & Sigma-Aldrich (286931) & $\begin{array}{l}1 \mu \mathrm{g} \text { C25 diluted in } 50 \\
\mu \mathrm{l} \text { isopropanol }\end{array}$ \\
\hline $\begin{array}{l}\text { Termite queen } \\
\text { pheromone }\end{array}$ & $\begin{array}{l}\text { n-butyl-n-butyrate and } \\
\text { 2-methyl-1-butanol }\end{array}$ & $\begin{array}{l}\text { n-butyl-n-butyrate } \\
\text { Sigma-Aldrich } \\
\text { (281964); 2-methyl-1- } \\
\text { butanol Wako } \\
\text { Chemicals (133-08385) }\end{array}$ & $\begin{array}{l}15 \mu \mathrm{l} \text { n-butyl-n-butyrate } \\
\text { and } 7.5 \mu \mathrm{l} 2 \text {-methyl-1- } \\
\text { butanol diluted in } 27.5 \\
\mu \mathrm{l} \text { isopropanol }\end{array}$ \\
\hline
\end{tabular}

\section{Ovary measurements}

Ovary collection for measurement was performed in triplicate and on the same day to prevent temporal changes in physiological measurements of ovaries. Ovary image identities were encoded such that they could be measured blind to reduce bias. Measurements were performed using ImageJ2 (55).

\section{RNA Sequencing}

For RNA sequencing, we randomly selected 4 vials and pulled 5 ovaries per vial. RNA extraction was performed with an in-house modified protocol (see supplemental material 1). Libraries were prepared using NEBNext ${ }^{\circledR}$ Ultra ${ }^{\mathrm{TM}}$ II Directional RNA Library Prep Kit (E7760L) for Illumina as instructed by the manufacturer. 


\section{Data Analysis}

The complete analysis pipeline and associated results is publicly available at https://github.com/marivelasque/eusociality evolution. This pipeline is a modified version of our previously developed pipeline (56). RNA data were trimmed with Trimmomatic 0.38 (57)and quality was assessed using FASTQC (58). Transcript abundance was calculated with RSEM/bowtie2 $(59,60)$. Mapping and abundance calculations were performed against the $D$. melanogaster genome assembly BDGP6 (release 89). Differential expression analysis was performed using edgeR (61). We adjusted $p$-values to control the false discovery rate using the Benjamini-Hochberg method. Threshold of significance was defined by $P<0.05$. Visualization relied on packages venn (62), ggplot2 (63), igraph (64) and ggraph (65). Analysis, figures and $\mathrm{html}$ file were generated using $\mathrm{R}$ in the RStudio environment.

\section{Gene co-expression network analysis}

We used two complementary approaches to investigate changes in gene network mediated by eusocial pheromones, eighted Gene Co-Expression Network Analysis WGCNA (66) and dcanr (67). We used the WGCNA R package to construct the coexpression network using gene counts obtained from RSEM. Prior to the analysis, we removed gene outliers using the "goodSamplesGenes" (66) function and accessed overall sample clustering in the expression matrix using "hclust" (68). We used the lowest threshold power that resulted in approximate scale-free topology to construct the gene co-expression network using the blockwiseModules function (66). Then, we estimated the gene expression profile, module eigengene, and the module-treatment relationship, calculating the correlation between the module eigengene and treatment group. We implemented the analysis in two steps (i.e. lowest threshold power and differential co-expression) using the functions SoftPower and wgcna.est from (56). Threshold of significance was defined by $\mathrm{P}<0.05$. 


\section{Enrichment and pathway analysis}

We obtained Gene Ontology and KEGG (Kyoto Encyclopedia of Genes and Genomes) annotations using the package biomaRt (69) clusterProfiler (68) respectively. We used Fisher's exact test to identify significantly enriched genes using the package topGO (70) with threshold of significance defined by $\mathrm{P}<0.05$. We identified enriched pathways using Pathway-Express, a package part of the Onto-Tools (71).

\section{Cross-species comparison}

To ensure pheromonal induced changes in the fruit fly transcriptome is comparable to eusocial insects, we compared the network conservation of eusocial insects and fruit flies exposed to pheromone. Holman et al. (22) compared the whole transcriptome of several species, including Apis mellifera and Bombus terrestris treated with either solvent-only control or their own species' queen pheromone. To determine whether the QMP network signature was well conserved between $D$. melanogaster, $A$. mellifera and $B$. terrestris, we used a WGCNA integrated function (modulePreservation) (66) to calculate module preservation statistics. Orthologs between these two groups were obtained using BLAST (see supplemental material S1) based on the D. melanogaster genome. Reads for Holman et al. (22) are deposited under the BioProject DRP004516. A total of 6125 unique $D$. melanogaster orthologs were identified in $A$. mellifera and 2099 in B. terrestris. To ensure that the conserved genes between the two data sets correspond to pheromone sensitive genes, we compared the differential expression between each QMP treatment and control using exactTest function in edgeR (61). Threshold of significance was defined by $P<0.05$. No publically available pheromone termite treatment data were identified.

\section{Declarations}

\section{Acknowledgements}

The Okinawa Institute of Science \& Technology Sequencing Centre kindly generated the sequencing data. Resources and expertise from the Okinawa Institute of 
Science \& Technology High Performance Computing Section were employed for data analysis.

\section{Funding}

The experiments and analysis were funded by the Okinawa Institute of Science \& Technology and JSPS KAKENHI Grants 19K16205 and 19K06795 awarded to MV and JAD respectively. MV, YT, AL, NML and JAD were supported by the Okinawa Institute of Science \& Technology.

\section{Availability of Data \& Materials}

All code is available at and a markdown file showing all analysis will be available on GitHub prior to publication https://github.com/marivelasque/eusociality evolution. All raw sequencing data will be made available prior to publication.

\section{Author Contributions}

MV and JAD conceived the project, designed and performed the experiments, analysed the results and wrote the paper. $\mathrm{YT}$ and $\mathrm{AL}$ prepared the sequencing libraries. All authors edited the manuscript and interpreted the results. 


\section{References}

1. J. M. Smith, E. Szathmary, The Major Transitions in Evolution (Oxford University Press, 1997; https://books.google.com/books/about/The_Major_Transitions_in_Evolution.html?hl $=\& \mathrm{id}=\mathrm{Qts} 6 \mathrm{FAcGGaIC}$ ).

2. T. D. Wyatt, Pheromones and Animal Behavior: Chemical Signals and Signatures (Cambridge University Press, 2014;

https://books.google.com/books/about/Pheromones_and_Animal_Behavior.html?hl $=\& \mathrm{id}=$ OCVOAgAAQBAJ).

3. F. G. Barth, A. Schmid, Ecology of Sensing (Springer Science \& Business Media, 2013; https://play.google.com/store/books/details?id=Yz3vCAAAQBAJ).

4. W. A. Searcy, Principles of Animal Communication. Second Edition. By Jack W. Bradbury and Sandra L. Vehrencamp. Sunderland (Massachusetts): Sinauer Associates. \$99.95. xiv 697 p.; ill. C-1-C-6 (credits) I-1-I-47 (index). ISBN: 978-087893-045-6. 2011. The Quarterly Review of Biology. 88 (2013), pp. 48-48.

5. N. M. A. El-Ghany, N. M. Abd El-Ghany, Pheromones and Chemical Communication in Insects. Pests - Classification, Management and Practical Approaches [Working Title] (2020), , doi:10.5772/intechopen.92384.

6. J. F. A. Traniello, S. K. Robson, Trail and Territorial Communication in Social Insects. Chemical Ecology of Insects 2 (1995), pp. 241-286.

7. C. G. Butler, Chemical Communication in Insects: Behavioral and Ecologic Aspects. Advances in Chemoreception (1970), pp. 35-78.

8. M. L. Winston, K. N. Slessor, Honey bee primer pheromones and colony organization: gaps in our knowledge. Apidologie. 29 (1998), pp. 81-95.

9. S. D. Leonhardt, F. Menzel, V. Nehring, T. Schmitt, Ecology and Evolution of 
Communication in Social Insects. Cell. 164, 1277-1287 (2016).

10. J. S. van Zweden, The evolution of honest queen pheromones in insect societies. Commun. Integr. Biol. 3, 50-52 (2010).

11. J. Olejarz, C. Veller, M. A. Nowak, The evolution of queen control over worker reproduction in the social Hymenoptera. Ecol. Evol. 7, 8427-8441 (2017).

12. G. C. Varley, E. O. Wilson, The Insect Societies. The Journal of Animal Ecology. 43 (1974), p. 261.

13. Y. L. Conte, Y. Le Conte, A. Hefetz, Primer Pheromones in Social Hymenoptera. Annual Review of Entomology. 53 (2008), pp. 523-542.

14. T. I. Szabo, Behavioural Studies on Queen Introduction in the Honeybee 3. Relationship Between Queen Attractiveness to Workers and Worker Aggressiveness towards a Queen. Journal of Apicultural Research. 13 (1974), pp. 161-171.

15. J. Beetsma, The Process of Queen-Worker Differentiation in the Honeybee. Bee World. 60 (1979), pp. 24-39.

16. S. Dobata, ARMS RACE BETWEEN SELFISHNESS AND POLICING: TWO-TRAIT QUANTITATIVE GENETIC MODEL FOR CASTE FATE CONFLICT IN EUSOCIAL HYMENOPTERA. Evolution. 66 (2012), pp. 3754-3764.

17. M. J. West-Eberhard, Phenotypic Plasticity and the Origins of Diversity. Annu. Rev. Ecol. Syst. 20, 249-278 (1989).

18. R. Gadagkar, R. Gadagkar, The Social Biology of Ropalidia marginata: toward understanding the evolution of eusociality (Harvard University Press, 2009; https://market.android.com/details?id=book-DgkCSMoySDUC).

19. S. H. Woodard, B. J. Fischman, A. Venkat, M. E. Hudson, K. Varala, S. A. Cameron, A. G. Clark, G. E. Robinson, Genes involved in convergent evolution of 
eusociality in bees. Proc. Natl. Acad. Sci. U. S. A. 108, 7472-7477 (2011).

20. A. J. Berens, J. H. Hunt, A. L. Toth, Comparative transcriptomics of convergent evolution: different genes but conserved pathways underlie caste phenotypes across lineages of eusocial insects. Mol. Biol. Evol. 32, 690-703 (2015).

21. M. R. Warner, L. Qiu, M. J. Holmes, A. S. Mikheyev, T. A. Linksvayer, Convergent eusocial evolution is based on a shared reproductive groundplan plus lineagespecific plastic genes. Nat. Commun. 10, 2651 (2019).

22. L. Holman, H. Helanterä, K. Trontti, A. S. Mikheyev, Comparative transcriptomics of social insect queen pheromones. Nat. Commun. 10, 1593 (2019).

23. L. Holman, Queen pheromones and reproductive division of labor: a meta-analysis. Behavioral Ecology (2018), , doi:10.1093/beheco/ary023.

24. G. D. Ruxton, S. Humphries, L. J. Morrell, D. M. Wilkinson, Why is eusociality an almost exclusively terrestrial phenomenon? J. Anim. Ecol. 83, 1248-1255 (2014).

25. K. M. Kapheim, H. Pan, C. Li, S. L. Salzberg, D. Puiu, T. Magoc, H. M. Robertson, M. E. Hudson, A. Venkat, B. J. Fischman, A. Hernandez, M. Yandell, D. Ence, C. Holt, G. D. Yocum, W. P. Kemp, J. Bosch, R. M. Waterhouse, E. M. Zdobnov, E. Stolle, F. B. Kraus, S. Helbing, R. F. A. Moritz, K. M. Glastad, B. G. Hunt, M. A. D. Goodisman, F. Hauser, C. J. P. Grimmelikhuijzen, D. G. Pinheiro, F. M. F. Nunes, M. P. M. Soares, E. D. Tanaka, Z. L. P. Simoes, K. Hartfelder, J. D. Evans, S. M. Barribeau, R. M. Johnson, J. H. Massey, B. R. Southey, M. Hasselmann, D. Hamacher, M. Biewer, C. F. Kent, A. Zayed, C. Blatti, S. Sinha, J. S. Johnston, S. J. Hanrahan, S. D. Kocher, J. Wang, G. E. Robinson, G. Zhang, Genomic signatures of evolutionary transitions from solitary to group living. Science. $\mathbf{3 4 8}$ (2015), pp. 1139-1143.

26. M. Orlova, J. Starkey, E. Amsalem, A small family business: synergistic and additive effects of the queen and the brood on worker reproduction in a primitively eusocial bee. J. Exp. Biol. 223 (2020), doi:10.1242/jeb.217547. 
27. J. Starkey, A. Brown, E. Amsalem, The road to sociality: brood regulation of worker reproduction in the simple eusocial bee Bombus impatiens. Anim. Behav. 154, 5765 (2019).

28. Y. Ulrich, D. Burns, R. Libbrecht, D. J. C. Kronauer, Ant larvae regulate worker foraging behavior and ovarian activity in a dose-dependent manner. Behav. Ecol. Sociobiol. 70, 1011-1018 (2016).

29. A. Maisonnasse, C. Alaux, D. Beslay, D. Crauser, C. Gines, E. Plettner, Y. Le Conte, New insights into honey bee (Apis mellifera) pheromone communication. Is the queen mandibular pheromone alone in colony regulation? Front. Zool. 7, 18 (2010).

30. A. Van Oystaeyen, R. C. Oliveira, L. Holman, J. S. van Zweden, C. Romero, C. A. Oi, P. d’Ettorre, M. Khalesi, J. Billen, F. Wackers, J. G. Millar, T. Wenseleers, Conserved Class of Queen Pheromones Stops Social Insect Workers from Reproducing. Science. 343 (2014), pp. 287-290.

31. C. F. Funaro, K. Böröczky, E. L. Vargo, C. Schal, Identification of a queen and king recognition pheromone in the subterranean termite Reticulitermes flavipes. Proceedings of the National Academy of Sciences. 115 (2018), pp. 3888-3893.

32. M. Lynch, J. S. Conery, The evolutionary demography of duplicate genes. J. Struct. Funct. Genomics. 3, 35-44 (2003).

33. E. V. Koonin, Orthologs, paralogs, and evolutionary genomics. Annu. Rev. Genet. 39, 309-338 (2005).

34. A. Kuzniar, R. C. H. J. van Ham, S. Pongor, J. A. M. Leunissen, The quest for orthologs: finding the corresponding gene across genomes. Trends Genet. 24, 539-551 (2008).

35. B. Misof, S. Liu, K. Meusemann, R. S. Peters, A. Donath, C. Mayer, P. B. Frandsen, J. Ware, T. Flouri, R. G. Beutel, O. Niehuis, M. Petersen, F. IzquierdoCarrasco, T. Wappler, J. Rust, A. J. Aberer, U. Aspöck, H. Aspöck, D. Bartel, A. 
Blanke, S. Berger, A. Böhm, T. R. Buckley, B. Calcott, J. Chen, F. Friedrich, M. Fukui, M. Fujita, C. Greve, P. Grobe, S. Gu, Y. Huang, L. S. Jermiin, A. Y. Kawahara, L. Krogmann, M. Kubiak, R. Lanfear, H. Letsch, Y. Li, Z. Li, J. Li, H. Lu, R. Machida, Y. Mashimo, P. Kapli, D. D. McKenna, G. Meng, Y. Nakagaki, J. L. Navarrete-Heredia, M. Ott, Y. Ou, G. Pass, L. Podsiadlowski, H. Pohl, B. M. von Reumont, K. Schütte, K. Sekiya, S. Shimizu, A. Slipinski, A. Stamatakis, W. Song, X. Su, N. U. Szucsich, M. Tan, X. Tan, M. Tang, J. Tang, G. Timelthaler, S. Tomizuka, M. Trautwein, X. Tong, T. Uchifune, M. G. Walzl, B. M. Wiegmann, J. Wilbrandt, B. Wipfler, T. K. F. Wong, Q. Wu, G. Wu, Y. Xie, S. Yang, Q. Yang, D. K. Yeates, K. Yoshizawa, Q. Zhang, R. Zhang, W. Zhang, Y. Zhang, J. Zhao, C. Zhou, L. Zhou, T. Ziesmann, S. Zou, Y. Li, X. Xu, Y. Zhang, H. Yang, J. Wang, J. Wang, K. M. Kjer, X. Zhou, Phylogenomics resolves the timing and pattern of insect evolution. Science. 346, 763-767 (2014).

36. K. C. Galang, J. R. Croft, G. J. Thompson, A. Percival-Smith, Analysis of the Drosophila melanogaster anti-ovarian response to honey bee queen mandibular pheromone. Insect Mol. Biol. 28, 99-111 (2019).

37. L. Aquiloni, E. Tricarico, Social Recognition in Invertebrates: The Knowns and the Unknowns (Springer, 2015; https://play.google.com/store/books/details?id=L1vACQAAQBAJ).

38. P. A. Hedin, J. J. Menn, Insect Chemical Communication (1988; https://books.google.com/books/about/Insect_Chemical_Communication.html?hl=\&i $\mathrm{d}=$ AqoiuwEACAAJ).

39. A. Hefetz, The critical role of primer pheromones in maintaining insect sociality. $Z$. Naturforsch. C. 74, 221-231 (2019).

40. G. V. Amdam, K. Norberg, M. K. Fondrk, R. E. Page Jr, Reproductive ground plan may mediate colony-level selection effects on individual foraging behavior in honey bees. Proc. Natl. Acad. Sci. U. S. A. 101, 11350-11355 (2004).

41. K. M. Weiss, A. V. Buchanan, Genetics and the Logic of Evolution (John Wiley \& 
Sons, 2004;

https://books.google.com/books/about/Genetics_and_the_Logic_of_Evolution.html? $\mathrm{hl}=$ \&id=9Dmm-HiSoYwC).

42. E. J. Duncan, O. Hyink, P. K. Dearden, Notch signalling mediates reproductive constraint in the adult worker honeybee. Nat. Commun. 7, 12427 (2016).

43. L. C. Ferguson, J. Green, A. Surridge, C. D. Jiggins, Evolution of the insect yellow gene family. Mol. Biol. Evol. 28, 257-272 (2011).

44. J. Schmitzová, J. Klaudiny, S. Albert, W. Schröder, W. Schreckengost, J. Hanes, J. Júdová, J. Simúth, A family of major royal jelly proteins of the honeybee Apis mellifera L. Cell. Mol. Life Sci. 54, 1020-1030 (1998).

45. M. D. Drapeau, S. Albert, R. Kucharski, C. Prusko, R. Maleszka, Evolution of the Yellow/Major Royal Jelly Protein family and the emergence of social behavior in honey bees. Genome Res. 16, 1385-1394 (2006).

46. G. Blomquist, R. Vogt, Insect Pheromone Biochemistry and Molecular Biology (Academic Press, 2020;

https://play.google.com/store/books/details?id=6bvbDwAAQBAJ).

47. Y. Le Conte, G. Arnold, J. Trouiller, C. Masson, B. Chappe, Identification of a brood pheromone in honeybees. Naturwissenschaften. 77, 334-336 (1990).

48. K. S. Traynor, Y. Le Conte, R. E. Page Jr, Queen and young larval pheromones impact nursing and reproductive physiology of honey bee (Apis mellifera) workers. Behav. Ecol. Sociobiol. 68, 2059-2073 (2014).

49. F. L. W. Ratnieks, H. Helanterä, The evolution of extreme altruism and inequality in insect societies. Philos. Trans. R. Soc. Lond. B Biol. Sci. 364, 3169-3179 (2009).

50. B. P. Oldroyd, K. E. Osborne, The evolution of worker sterility in honeybees: the genetic basis of failure of worker policing. Proceedings of the Royal Society of London. Series B: Biological Sciences. 266, 1335-1339 (1999). 
51. W. O. H. Hughes, B. P. Oldroyd, M. Beekman, F. L. W. Ratnieks, Ancestral monogamy shows kin selection is key to the evolution of eusociality. Science. 320, 1213-1216 (2008).

52. M. A. Nowak, C. E. Tarnita, E. O. Wilson, The evolution of eusociality. Nature. 466, 1057-1062 (2010).

53. T. L. Pritchett, E. A. Tanner, K. McCall, Cracking open cell death in the Drosophila ovary. Apoptosis. 14, 969-979 (2009).

54. M. Buszczak, L. Cooley, Eggs to die for: cell death during Drosophila oogenesis. Cell Death Differ. 7, 1071-1074 (2000).

55. C. T. Rueden, J. Schindelin, M. C. Hiner, B. E. DeZonia, A. E. Walter, E. T. Arena, K. W. Eliceiri, ImageJ2: ImageJ for the next generation of scientific image data. BMC Bioinformatics. 18, 529 (2017).

56. J. A. Denton, M. Velasque, F. A. Reed, Cross-species Transcriptomic Network Analysis Reveals Links Between Ribosomal Protein Mutation and Cancer, , doi:10.1101/2020.12.11.420604.

57. A. M. Bolger, M. Lohse, B. Usadel, Trimmomatic: a flexible trimmer for Illumina sequence data. Bioinformatics. 30 (2014), pp. 2114-2120.

58. S. Andrews, FastQC: a quality control tool for high throughput sequence data. Babraham Bioinformatics (2010), (available at http://www.bioinformatics.babraham.ac.uk/projects/fastqc).

59. B. Li, C. N. Dewey, RSEM: accurate transcript quantification from RNA-Seq data with or without a reference genome. BMC Bioinformatics. 12, 323 (2011).

60. B. Langmead, S. L. Salzberg, Fast gapped-read alignment with Bowtie 2. Nat. Methods. 9, 357-359 (2012).

61. M. D. Robinson, D. J. McCarthy, G. K. Smyth, edgeR: a Bioconductor package for 
differential expression analysis of digital gene expression data. Bioinformatics. 26, 139-140 (2010).

62. A. Dusa, Venn: draw venn diagrams. $R$ package version (2018) (available at https://scholar.google.ca/scholar?cluster=15836897736285395508\&hl=en\&as_sdt= $0,5 \&$ sciodt $=0,5)$.

63. L. Wilkinson, ggplot2: Elegant Graphics for Data Analysis by WICKHAM, H. Biometrics. 67 (2011), pp. 678-679.

64. G. Csardi, T. Nepusz, Others, The igraph software package for complex network research. InterJournal, complex systems. 1695, 1-9 (2006).

65. B. Si, Y. Liang, J. Zhao, Y. Zhang, X. Liao, H. Jin, H. Liu, L. Gu, GGraph: An Efficient Structure-aware Approach for Iterative Graph Processing. IEEE Transactions on Big Data, 1-1 (2020).

66. P. Langfelder, S. Horvath, WGCNA: an R package for weighted correlation network analysis. BMC Bioinformatics. 9, 559 (2008).

67. D. D. Bhuva, J. Cursons, M. J. Davis, dcanr: Differential co-expression/association network analysis (2018).

68. G. Yu, L.-G. Wang, Y. Han, Q.-Y. He, clusterProfiler: an R Package for Comparing Biological Themes Among Gene Clusters. OMICS. 16, 284-287 (2012).

69. S. Durinck, Y. Moreau, A. Kasprzyk, S. Davis, B. De Moor, A. Brazma, W. Huber, BioMart and Bioconductor: a powerful link between biological databases and microarray data analysis. Bioinformatics. 21, 3439-3440 (2005).

70. A. Alexa, J. Rahnenführer, Gene set enrichment analysis with topGO. Bioconductor Improv. 27, 1-26 (2009).

71. S. Draghici, P. Khatri, P. Bhavsar, A. Shah, S. A. Krawetz, M. A. Tainsky, OntoTools, the toolkit of the modern biologist: Onto-Express, Onto-Compare, Onto- 
bioRxiv preprint doi: https://doi.org/10.1101/2021.07.11.451940; this version posted July 14, 2021. The copyright holder for this preprint (which was not certified by peer review) is the author/funder. All rights reserved. No reuse allowed without permission.

Design and Onto-Translate. Nucleic Acids Res. 31, 3775-3781 (2003). 
bioRxiv preprint doi: https://doi.org/10.1101/2021.07.11.451940; this version posted July 14, 2021. The copyright holder for this preprint (which was not certified by peer review) is the author/funder. All rights reserved. No reuse allowed without permission. 